\title{
Saúde, governo e mídia: uma relação (por vezes) conflituosa
}

Health, government and media:

a (sometimes) conflictive relationship

Salud, gobierno y medios:

una relación (a veces) conflictiva

\section{Isaltina Maria de Azevedo Mello Gomes}

- Doutora e mestre em Linguística pela Universidade Federal de Pernambuco (UFPE)

- Especialista em Produção de Programas Radiofônicos pelo Ciespal (Quito/Equador)

- Graduada em Letras pela Faculdade de Filosofia do Recife (Fafire) e em Comunicação Social - Jornalismo pela UFPE

- Professora de Jornalismo e do Programa de Pós-Graduação em Comunicação da UFPE

- Membro do Comitê Temático de Divulgação Científica do CNPq (2011-...)

- Trabalha com questões relacionadas à linguagem nos meios de comunicação, mas tem interesse especial pela área de divulgação científica

- E-mail: isaltina@gmail.com

\section{Luiz Marcelo Robalinho Ferraz}

- Doutorando no Programa de Pós-graduação em Informação e Comunicação em Saúde da Fundação Oswaldo Cruz (Fiocruz)

- Mestre em Comunicação pela Universidade Federal de Pernambuco (UFPE)

- Graduado em Jornalismo pela Universidade Católica de Pernambuco (Unicap) e em Publicidade e Propaganda pela UFPE

- Sua área de interesse é a comunicação em saúde, com ênfase na memória discursiva sobre moléstias e na concepção midiática de doença

- E-mail: marcelorobalinho@yahoo.com.br 


\section{Resumo}

O objetivo deste artigo é analisar os conflitos entre mídia e governo na divulgação de doenças. Selecionamos as 46 matérias publicadas sobre febre amarela no Jornal do Commercio e no Diario de Pernambuco, do Recife (PE) entre 7 de janeiro e 19 de fevereiro de 2008, em uma cobertura polêmica sobre a ocorrência de uma possível epidemia, apesar de o governo ter negado o fato. Avaliamos secundariamente a epidemia de meningite meningocócica no Brasil nos anos 1970. Tomamos como base os conceitos de risco e memória discursiva para compreender os sentidos construídos tanto em períodos ditatoriais quanto nos de democracia.

PALAVRAS-CHAVE: DISCURSO JORNALÍSTICO • EPIDEMIA • FEBRE AMARELA • MENINGITE MENINGOCÓCICA • RISCO

\section{Abstract}

The purpose of this article is of analyzing the conflicts between the media and the government in the divulgement of diseases. We have selected the 46 subjects published on yellow fever in the Jornal do Commercio and in the Diário de Pernambuco, of Recife (PE), from January 7 to February 19,2008 , in a controversial coverage concerning the occurrence of a possible epidemic, despite the government having denied the fact. We assessed secondarily the meningococcal meningitis epidemic in Brazil in the1970s. We used as a base the concepts of risk and discursive memory to understand the senses developed both in the dictatorial and democratic periods.

KEYWORDS: JOURNALISTIC DISCOURSE • EPIDEMIC • YELLOW FEVER・ MENINGOCOCCAL MENINGITIS • RISK

\section{Resumen}

El objetivo de este artículo es analizar los conflictos entre los medios y el gobierno en la divulgación de enfermedades. Seleccionamos las 46 materias publicadas sobre fiebre amarilla en el Jornal do Commercio y en el Diario de Pernambuco, de Recife (PE) entre 7 de enero y 19 de febrero de 2008, en una cobertura polémica sobre el brote de una posible epidemia, a pesar de el gobierno haber negado ese hecho. Evaluamos secundariamente la epidemia de meningitis meningocócica en el Brasil en los años 1970. Tomamos como base los conceptos de riesgo y memoria discursiva para comprender los sentidos construidos tanto en períodos dictatoriales cuanto en los de democracia.

PALABRAS CLAVE: DISCURSO PERIODÍSTICO • EPIDEMIA • FIEBRE AMARILLA • MENINGITIS MENINGOCÓCICA・RIESGO 
$\mathbf{N}$ o início de 2008, a febre amarela chamou a atenção da sociedade. Apesar de não se terem registrados casos em ambientes urbanos desde 1942, o aumento de notificações acima do normal e a ocorrência de mortes levaram os meios de comunicação a publicar uma série de notícias insinuando o retorno da moléstia e a ocorrência de uma possível epidemia no país. Negado pelo poder público, o fato se converteu numa polêmica, acarretando uma cobertura com informações por vezes contraditórias, já que havia a suspeita de que o governo estivesse escondendo ou minimizando os dados.

Amparados nas noções de risco e memória discursiva, fundamentais para compreensão dos sentidos criados sobre doenças infecciosas, acreditamos que o reconhecimento de uma epidemia e o momento certo de divulgá-la está longe de ser um ponto de consenso. Em alguns casos, pode provocar a adoção de antigas práticas assumidas pelas autoridades em contextos de fechamento político, como nas ditaduras, quando a informação tende a ser escamoteada ou mesmo sonegada em nome do "bem-estar" coletivo, a exemplo do que ocorreu com a epidemia de meningite meningocócica na década de 1970 no Brasil. Em outros casos, pode causar pânico pelo superdimensionamento da doença, como aconteceu com a febre amarela em 2008.

Levando em conta a riqueza discursiva da situação epidemiológica "atípica" envolvendo a febre amarela, selecionamos as 46 matérias publicadas pelos periódicos pernambucanos Jornal do Commercio e Diario de Pernambuco entre 7 de janeiro e 19 de fevereiro daquele ano. Paralelamente, avaliamos o texto do pronunciamento do então ministro da Saúde, José Gomes Temporão, em cadeia nacional de televisão. Embora Pernambuco não tenha sido considerado área de risco para a febre amarela, o fato de a mídia ter encarado a doença como epidemia em boa parte do país reverberou diretamente no estado, bem como em outras localidades. Isso levou a população a uma busca desenfreada pela vacina para se proteger contra o vírus, reeditando-se, às avessas, a Revolta da Vacina, protesto popular ocorrido em 1904 no Rio de Janeiro contra a medida governamental de imunizar a população compulsoriamente contra a varíola (Ujvari, 2003). Já em relação à meningite, recuperamos uma reportagem veiculada pela revista Veja em 4 de outubro de 1972, em pleno auge da epidemia, a fim de ilustrar a situação vivenciada durante a ditadura.

\section{O "FANTASMA" DA EPIDEMIA}

A epidemia se caracteriza como a ocorrência de doença em um número de pessoas acima do esperado (Rouquayrol; Almeida Filho, 2003). Apesar de ser um fenômeno coletivo, ela possui uma singularidade histórica que a individualiza no tempo e no espaço (Foucault, 2006, p. 26), expressando-se de diferentes formas no contexto social, econômico, político e cultural. Ao longo da história, a concepção das epidemias variou bastante. Os povos antigos acreditavam que as infecções eram enviadas pelos deuses, muitas vezes como ação benéfica. Por muito tempo, a origem das epidemias foi considerada uma incógnita, dando margem a diversas interpretações. 
Embora as epidemias já fossem conhecidas muito antes da invenção da imprensa, ganharam maior visibilidade com o advento dos media, facilitando a difusão de informações para um grande número de pessoas. A nosso ver, a imprensa tratou de reforçar o medo e a dor que nortearam a construção dos discursos, tomando como base a memória das antigas pragas, a exemplo da peste negra. Falar de epidemia nos remete a um contexto de desordem e pânico causados pelo caráter acidental da doença em larga escala, provocando mortes e afetando a rotina das cidades. Evidentemente, as pessoas já não mais creditam as epidemias a forças maléficas ou ao castigo divino de um deus, como antes. Com o desenvolvimento da ciência e a elucidação do papel das bactérias como causadoras das doenças infecciosas em meados do século XIX, a teoria dos ares impuros (miasmas) - possuidores de substâncias nocivas - foi caindo em desuso. O meio ambiente e suas condições passaram a ser o foco das atenções dos estudos em saúde e o homem foi desmistificando velhas crenças e superstições.

Discursivamente, porém, não podemos deixar de lado os sentidos antigos na construção de uma noção pública de epidemia, a partir do momento em que consideramos o passado fundamental para a compreensão sobre doenças. Isso é mais forte com as enfermidades infecciosas, que guardam um pouco daquele medo secular, se levarmos em conta eventos epidemiológicos recentes que chamaram a atenção da mídia, como a epidemia explosiva de dengue em Pernambuco em 2002 (Ferraz, 2010) e a pandemia de gripe A (H1N1) no mundo (Gomes; Ferraz, 2010).

Para a análise do discurso, a epidemia pode ser entendida por tudo o que foi dito a respeito dela, pelo conjunto de formulações que a designam no tempo e no espaço. "Não há enunciado que não suponha outros; não há nenhum que não tenha, em torno de si, um campo de coexistências, efeitos de série e de sucessão, uma distribuição de função e papéis" (Foucault, 2007, p. 112). Na análise do discurso, a memória tem um papel importante na construção dos discursos por "invocar" sentidos existentes em outros enunciados. Ela se articula com o conceito de interdiscurso, considerado o conjunto de discursos que dialogam entre si, mantendo uma "delimitação recíproca" e com o qual "um discurso particular entra em relação implícita ou explícita", conforme Patrick Charaudeau e Dominique Maingueneau (2008, p. 286) (Grifo dos autores).

Sobre o assunto, Eni P. Orlandi (2007, p. 135-136) diz que a noção de historicidade é fundamental para se compreender as relações de sentido.

Para que uma palavra faça sentido é preciso que ela já tenha sentido. Essa impressão do significar deriva do que se tem chamado [de] "interdiscurso". Isto é, o domínio do "saber" discursivo, o da sua memória, aquele que sustenta o dizer numa estratificação de formulações já feitas mas "esquecidas" e que vão construindo uma história dos sentidos. Toda fala resulta assim de um efeito de sustentação no já-dito que, por sua vez, só funciona quando as vozes que se poderiam identificar em cada formulação particular se apagam e trazem o sentido para o regime do "anonimato" e da "universalidade". Ilusão de que o sentido nasce ali, não tem história. 
Pensando na saúde dentro do viés interdiscursivo, a noção de risco torna-se central, sobretudo em contextos de calamidade, como as epidemias, pelo caráter imprevisível que costuma levar a uma produção de notícias acima da média. Apesar de serem vistas como um agente externo, as epidemias estão diretamente ligadas ao corpo individual e social. É a partir dele que a doença se manifesta, torna-se real aos olhos e se dissemina para outros corpos. Noção complexa, por se tratar de uma representação do perigo (e não a catástrofe em si), o risco "designa, ao mesmo tempo, tanto um perigo potencial quanto sua percepção e indica uma situação percebida como perigosa na qual se está ou cujos efeitos podem ser sentidos" (Veyret; Richemond, 2007, p. 25).

Embora a nossa saúde seja ditada atualmente pelos fatores de risco (características do indivíduo ou do seu ambiente que aumentam as chances de se adoecer) nas doenças crônicas não-transmissíveis, a ideia de causalidade ainda está bastante presente, sobretudo porque as doenças infecciosas respondem por mais de $25 \%$ das mortes anuais no mundo (Silva; Angerami, 2008). Articulada à compreensão das doenças infecciosas, a causalidade dita a experiência de adoecimento, determinando a origem a um agente patogênico externo (vírus e bactérias, por exemplo). Assim, ela se alia à noção de risco para explicar o significado da enfermidade, sobretudo por meio da imprensa, que busca uma explicação causal nos assuntos ligados a saúde-doença a fim de conferir maior objetividade à narrativa e torná-la mais fácil de ser assimilada.

\section{MENINGITE MENINGOCÓCICA E FEBRE AMARELA NA COBERTURA JORNALÍSTICA}

Entre as doenças infecciosas, a meningite meningocócica é uma das que mais desperta a atenção, mesmo na ocorrência de casos isolados sem qualquer relação com surtos ou epidemias. Caracterizada pela inflamação das meninges (membranas que revestem o cérebro), a doença pode matar, caso não seja tratada adequadamente. O fácil contágio entre pessoas próximas por meio de gotículas e secreções do nariz e da garganta sempre é motivo de preocupação quando alguma ocorrência nova é registrada. A busca por medicação para prevenir e tratar a doença, em decorrência do medo de contaminação, também se torna algo bastante comum, mesmo quando a situação não demanda o uso de remédios.

Falar de meningite meningocócica nos reporta aos anos 1970, quando o Brasil viveu uma grande epidemia, levando à morte de milhares de pessoas. A divulgação da doença foi alvo de forte censura nos primeiros anos da década por parte do governo militar, que determinou o assunto como "questão de segurança nacional". Veículos de comunicação foram proibidos de fazer qualquer alusão à epidemia, tendo as matérias previamente avaliadas e editadas, especialmente em São Paulo, onde a incidência da meningite foi muito alta, atingindo a taxa de 169 casos por 100 mil habitantes, em 1974. Mesmo com a progressão da doença, as autoridades tentaram minimizar o fato, sonegando informações, atitude criticada pela imprensa (Barata, 1988). 
A reportagem "A epidemia nacional do medo", publicada na revista Veja em 4 de outubro de 1972, ilustra um pouco aquele momento:

\begin{abstract}
Enquanto puderam, as autoridades sanitárias guardaram um sigilo do qual até agora devem se arrepender. Até que, na terça-feira passada, a Secretaria de Saúde de São Paulo distribuiu um comunicado recomendando cuidados "diante da atual ocorrência de meningite meningocócica na capital e outros municípios". (...) Alarmada, sem o amparo de índices oficiais, a população iniciou então uma corrida aos pediatras e hospitais. (...) E quando cidades inteiras se alarmaram, o mesmo costume de não informar estabeleceu-se nas relações das autoridades com a imprensa, sistematicamente tratada com desconfiança (Veja, 1972, p. 24-28).
\end{abstract}

Além de não fornecerem informações precisas, autoridades acusavam a imprensa de alarmar a população. Em parte, isso revela o autoritarismo característico dos períodos de ditadura, com a centralização em todos os níveis de organização do Estado, a predominância absoluta do Poder Executivo em relação aos demais e a censura. Relações tensas entre poder público e imprensa não são típicas apenas em contextos ditatoriais. Mesmo com a redemocratização do país, o governo alegou em determinados momentos que a população era despreparada para receber informações sobre a meningite e que só aos técnicos interessaria saber se havia epidemia ou não, em nome da "preservação da tranquilidade"1.

Mais recentemente, o episódio da febre amarela reacendeu o embate, só que num outro contexto político. A confirmação da primeira morte pela doença, no final de dezembro de 2007, e o aumento do número de mortes de macacos em áreas de mata levaram os órgãos de vigilância a adotar estratégias de controle, atraindo a atenção da imprensa no começo de 2008. O fato foi logo encarado como uma epidemia, provocando uma verdadeira corrida da população aos postos de saúde em busca da vacina que previne a doença. As tentativas do governo de explicar a situação, que incluíram notas pagas nos jornais de maior circulação no país, foram em vão, revelando a desconfiança da imprensa quanto às declarações oficiais. Nas manchetes e chamadas, houve uma escalada a respeito da febre amarela, em contraposição a declarações, dados e informes divulgados quase que diariamente pelo Ministério da Saúde ${ }^{2}$. No Jornal do Commercio e no Diario de Pernambuco, foram verificadas 46 matérias, além de treze chamadas de capa, entre 7 de janeiro e 19 de fevereiro daquele ano.

\footnotetext{
1 Entre 1986 e 1987, durante outra epidemia de meningite em São Paulo, observaram-se duas posturas distintas por parte das autoridades: de um lado, negando a situação e, de outro, confirmando a existência do problema e buscando conscientizar a população. A ocorrência de casos em outros oito estados levou o Ministério da Saúde a emitir nota informando que o fato caracterizaria um pré-surto, "pelo aumento do número de casos da doença em épocas frias", sendo em seguida negado pelo ministro da Saúde, Borges da Silveira. Poucos meses depois, o ministério divulgou outra nota confirmando a epidemia em treze estados, incluindo Pernambuco. Desses, quatro negaram (Barata, 1990).

${ }^{2}$ Contabilizamos 45 divulgações oficiais do governo sobre a situação da febre amarela no site do Ministério da Saúde (www. saude.gov.br) no período citado.
} 
Destacamos o texto publicado no dia 10 de janeiro de 2008 no Diario, informando o posicionamento do ministério e negando a ocorrência de uma epidemia:

O governo federal intensificou uma campanha de prevenção contra a febre amarela e enviou um alerta internacional após o crescimento do número de casos da doença, mas o Ministério da Saúde negou ontem que haja risco de epidemia. Em entrevista coletiva, o ministro da Saúde, José Gomes Temporão, disse que a situação está "sob controle" e que não há casos de febre amarela urbana no Brasil, nem riscos de epidemia (DP, 2008a).

Em 20 de janeiro, foi a vez de o Jornal do Commercio veicular uma matéria a respeito do mesmo assunto. Nesse caso, a informação da negativa da epidemia veio metaforizada por uma comparação (as autoridades do Ministério da Saúde têm repetido como um mantra que não há risco de uma nova epidemia da doença), além da crítica de um especialista sobre a atitude do governo de exagerar na recomendação da imunização na forma de discurso indireto:

Desde que os casos de febre amarela pipocaram no país, as autoridades do Ministério da Saúde têm repetido como um mantra que não há risco de uma nova epidemia da doença. (...) Um dos maiores especialistas em doenças tropicais no mundo, Luiz Hildebrando Pereira da Silva, diz que o governo poder ter exagerado ao estender a recomendação de vacinação contra a febre amarela para além de áreas de mata, conforme instrução divulgada pelo Ministério da Saúde brasileiro. A recomendação do governo abrange também áreas urbanas. A vacina traz riscos, destaca, e deve ser administrada com cuidado (Carvalho, 2008).

Grosso modo, os mantras são orações usadas no hinduísmo e expressas em sons, palavras, frases ou textos com determinado poder, uma espécie de energia que movimenta outras energias em volta de quem o entoa. No caso da matéria, a repetição das autoridades públicas de que o país não estava vivendo uma epidemia evidenciou como a metáfora foi utilizada para reforçar a negação frente à desconfiança.

De 16 de dezembro de 2007 a 2 de abril de 2008, o ministério notificou setenta casos suspeitos de febre amarela, dos quais quarenta foram confirmados e 21 evoluíram para óbito (MS, 2008). A suspeita de que o governo estava "escondendo" alguma informação levou o ministro da Saúde, José Gomes Temporão, a fazer um pronunciamento na televisão em horário nobre no domingo 13 de janeiro de 2008 para tranquilizar a população. Eis o texto:

Estou aqui para tranquilizar a população brasileira sobre um assunto que está preocupando os brasileiros nos últimos dias. O temor de que esteja ocorrendo uma epidemia de febre ama- 
rela no país. Não existe risco de epidemia. O Brasil não tem casos de febre amarela urbana desde 1942. Os casos registrados de lá para cá foram todos de febre amarela silvestre, ou seja, de pessoas que contraíram a doença nas florestas. Desde 2003, a ocorrência de febre amarela silvestre em seres humanos vem caindo gradativamente. Os casos suspeitos estão localizados e restritos a áreas onde algumas pessoas não vacinadas entraram em florestas e matas nas últimas semanas. O Ministério da Saúde tomou todas as medidas preventivas para evitar que casos da doença aparecessem antes mesmo da confirmação do caso sob investigação. Montamos uma grande barreira sanitária nas áreas de risco protegendo estados e municípios contra a febre amarela. E, de imediato, convocamos as pessoas que vão viajar ou moram em áreas de mata para tomar a vacina. Se você não mora ou não viajar para essas regiões não precisa se vacinar. Quem já se vacinou pode ficar tranquilo: o efeito da vacina protege as pessoas durante dez anos. Portanto, só procure os postos de saúde se morar ou for visitar as áreas de risco e nunca se vacinou ou foi vacinado antes de 1999. Mas, lembre-se, tomando a vacina, você estará totalmente protegido após dez dias. O Brasil é o maior produtor mundial de vacina contra a febre amarela. Os postos de saúde estão sendo abastecidos e as autoridades sanitárias estão preparadas para atender a quem realmente precisa tomar a vacina. Muito obrigado e boa noite ${ }^{3}$.

É possível perceber a ênfase dada pelo Ministério de que não havia risco de epidemia, apesar do temor existente. Observamos doze trechos que reforçam a segurança do país, sendo seis enfatizando a postura do governo diante da situação da febre amarela naquele momento e outros seis ressaltando a importância da vacina e o esquema montado para dar conta da imunização das pessoas que fossem eventualmente viajar para áreas de mata. O objetivo era tranquilizar a população, deixando claro que o país não tinha casos de febre amarela nos ambientes urbanos desde a década de 1940 e que a União estava tomando todas as medidas de controle. As marcas textuais no pronunciamento evidenciam a importância dada às declarações negativas, com objetivo de afastar a possibilidade de risco (uso do advérbio "não"), bem como a ênfase dada às ações preventivas e à necessidade de as pessoas procurarem os postos para se vacinarem contra a doença caso morassem em áreas de mata ou viajassem para regiões do tipo. O quadro 1 destaca esses trechos:

\footnotetext{
3 Texto do pronunciamento do ministro de Saúde José Gomes Temporão veiculado em cadeia nacional de televisão em 13 de janeiro de 2008 (MS, 2008).
} 
Quadro 1 - A segurança do país em relação à febre amarela no pronunciamento do ministro da Saúde

\begin{tabular}{|c|c|}
\hline $\begin{array}{l}\text { Ênfase na tranquilização } \\
\text { da população }\end{array}$ & $\begin{array}{l}\text { Estou aqui para tranqüilizar a população brasileira } \\
\text { não existe risco de epidemia. } \\
\text { Brasil não tem casos de febre amarela urbana desde } 1942 . \\
\text { Ocorrência de febre amarela silvestre em seres humanos vem } \\
\text { caindo gradativamente. } \\
\text { Ministério da Saúde tomou todas as medidas preventivas } \\
\text { montamos uma grande barreira sanitária nas áreas de risco. }\end{array}$ \\
\hline $\begin{array}{l}\text { Enfase na importância } \\
\text { da vacina e no esquema } \\
\text { de imunização montado }\end{array}$ & $\begin{array}{l}\text { Convocamos as pessoas que vão viajar ou moram em áreas } \\
\text { de mata para tomar a vacina. } \\
\text { Quem já se vacinou pode ficar tranquilo: o efeito da vacina pro- } \\
\text { tege as pessoas durante dez anos. } \\
\text { Só procure os postos de saúde se morar ou for visitar as áreas } \\
\text { de risco e nunca se vacinou ou foi vacinado antes de } 1999 \text {. } \\
\text { Tomando a vacina, você estará totalmente protegido após dez } \\
\text { dias. } \\
\text { Brasil é o maior produtor mundial de vacina contra a febre } \\
\text { amarela. } \\
\text { Postos de saúde estão sendo abastecidos e as autoridades } \\
\text { sanitárias estão preparadas para atender a quem realmente } \\
\text { precisa tomar a vacina }\end{array}$ \\
\hline
\end{tabular}

O manual da redação da Folha de S.Paulo (FSP, 1992, p. 72) faz uma ressalva quanto ao posicionamento do governo frente a epidemias: "É comum autoridades da área de saúde negarem a existência ou protelarem a divulgação de epidemias, sob o argumento de não criar pânico". A restrição revela a descrença da imprensa no especialista público, corroborando a ideia de que, mesmo em regimes democráticos, a relação entre os governos e os meios apresenta conflitos. 
Evidentemente, o contexto sociopolítico durante a divulgação de notícias sobre a meningite na década de 1970 e a febre amarela nos anos 2000 é completamente diferente. Mas ambas as doenças guardam entre si aquela "cicatriz" discursiva que a memória da epidemia costuma suscitar, promovendo novos rearranjos entre o esquecer e o lembrar sobre as doenças potencialmente epidêmicas, além de levantar questões antigas na relação entre o Estado e a imprensa. Pernambuco, que não estava situado nas áreas de risco, vivenciou o pânico gerado pela mídia. A seguir, destacamos a primeira matéria que tratou da sobrecarga ocorrida nos postos de saúde pela procura da população pela vacina. Ela foi publicada no dia 12 de janeiro na editoria de Cidades, como matéria principal de capa do caderno:

A excessiva procura por vacina contra febre amarela nos postos do Recife está preocupando a Secretaria Municipal de Saúde, representantes locais da Agência Nacional de Vigilância Sanitária e técnicos do setor. Num dia e meio, os oito postos municipais que oferecem a vacina na capital imunizaram 1.471 pessoas. (...) "Se essa demanda crescer muito, pode faltar vacina para quem precisa”, alerta Graça Cavalcanti, diretora de Atenção à Saúde do Recife.

Ela apela para que só as pessoas com destino a áreas de risco para a febre amarela compareçam aos postos. Mas não é isso que está ocorrendo. Além dos viajantes, moradores do Recife e de outras cidades sem viagem programada têm buscado a vacina. "Se a doença chegar por aqui quero estar protegida", disse a dona de casa Maria Rita da Silva, que procurou ontem o Lessa de Andrade e foi orientada a voltar para casa.

(...)

Para garantir que só os viajantes para área de risco tenham acesso à vacina, os postos estão exigindo comprovantes, como bilhete da passagem ou outro documento que comprove a ida (JC, 2008a)

O conflito provocou a ida de milhares de pernambucanos aos postos de saúde do Recife, os únicos que estavam vacinando em todo o estado. O fato levou a Secretaria de Saúde a limitar a vacinação às pessoas que apresentavam algum comprovante de viagem para áreas de mata do Centro-Oeste e algumas regiões de Goiás e Mato Grosso do Sul, diante do risco do fim do estoque da vacina no estado e da preocupação com a falta de informação das pessoas. A grande procura acabou desabastecendo os postos, conforme matéria publicada em 25 de janeiro no Diario de Pernambuco:

A grande procura pela vacina contra febre amarela já trouxe consequências em Pernambuco. Na terça e quarta-feira desta semana, houve desabastecimento do produto nos nove postos de saúde que oferecem a imunização no Recife. De acordo com Graça Cavalcante, diretora geral de atenção à saúde da Secretaria de Saúde do Recife, desde o dia 7 de janeiro, a procura pela vacinação cresceu consideravelmente. Foram 720 aplicações por dia, enquanto até o final do ano passado, este número era de dezessete.

Ontem, os postos de saúde do estado receberam reforço. De acordo com a técnica do Progra- 
ma de Imunização de Pernambuco Adriana Baltar, foram 15 mil doses distribuídas às unidades de vacinação. "São cinco mil a mais do que recebemos normalmente. Pedimos este reforço por causa do carnaval, quando muitos viajam pelo país", explica.

Graça e Adriana afirmam que as dosagens são suficientes para atender a demanda dos viajantes que se dirigem a áreas de risco, principalmente o Centro-Oeste do país. "Se as pessoas se conscientizarem e tomarem a vacina apenas nesta circunstância, não teremos desabastecimentos", diz Graça Cavalcante (Sotero, 2008).

Pela fala da gestora, verifica-se a ênfase dada à conscientização a fim de garantir a normalidade. A matéria que havia saído dois dias antes, em 23 de janeiro, desta vez no Jornal do Commercio, já revelava a situação da imunização desnecessária no Brasil:

Quase 1 milhão de pessoas se vacinaram contra febre amarela em Goiás sem necessidade desde dezembro.

(...)

Um balanço do governo do estado aponta que 3,4 milhões de pessoas tomaram a vacina desde 17 de dezembro, quando a morte de macacos por febre amarela provocaram [sic] uma corrida aos postos do estado - que tem 5,6 milhões de habitantes.

As imunizações desnecessárias correspondem a $29 \%$ do total de vacinados. Oito pessoas já morreram este ano após contrair febre amarela no estado. Outras duas mortes suspeitas estão sob análise (JC, 2008b).

Pelos cálculos, $29 \%$ dos quase 1 milhão de vacinados tomaram a dose sem precisar. Além de se configurar numa situação preocupante, o episódio nos remeteu à histórica Revolta da Vacina, ocorrida no Rio de Janeiro em 1904, devido à vacinação obrigatória imposta para imunizar a população contra a varíola (Ujvari, 2003). A ida de centenas de milhares de brasileiros aos postos em 2008 revelou uma espécie de revolta às avessas. Diante do desentendimento causado entre imprensa e autoridades quanto à declaração ou não de "epidemia" e o temor de que o país estivesse vivendo uma situação de descontrole, como os eventos epidêmicos costumam suscitar na memória das pessoas, a "luta" agora era individual. A finalidade era assegurar a proteção do organismo humano, indicando sutilmente a força e legitimidade do discurso científico obtidas nos últimos séculos.

\section{REFERÊNCIAS FINAIS}

Analisando os episódios de meningite e febre amarela, constatamos que relações de conflito entre autoridades e imprensa nunca deixaram de existir. Apenas tendem a ser mais acentuadas durante regimes autoritários. Para nós, o reconhecimento de uma epidemia e o momento certo de divulgá-la está longe de ser um ponto de consenso, podendo levar a situações completamente distintas. A análise das duas coberturas é um indicativo dessa dificuldade. 
Com a febre amarela em 2008, apesar de não ter se configurado realmente em epidemia, a exemplo do que tinha sido com a meningite nos anos 1970, o caso revela um pouco dos obstáculos que permeiam a divulgação de situações de risco. Ao trazer à tona noções seculares que envolvem as moléstias, como medo, mal, morte, risco e epidemia (Ferraz, 2010), a memória discursiva confere representatividade às doenças infecciosas no meio social, determinando a forma como elas são encaradas. Por serem permeados pela memória de moléstias epidêmicas do passado, os novos discursos sofrem uma influência dos sentidos anteriores para significar a experiência da doença.

No episódio da febre amarela, a polêmica trouxe lições. Uma delas foi que o impacto do noticiário na construção de discursos alarmistas poderia ter tido conseqUências mais sérias na opinião pública. A principal delas dizia respeito à superdose de vacinas. Pelo menos 43 pessoas foram internadas com sintomas da "overdose", por terem tomado duas e até três vezes a vacina (DP, 2008b). O pânico comprometeu também o estoque de doses, obrigando o governo a produzir mais vacinas.

Todo esse alarde teve influência direta da mídia na politização de um episódio, dando a ideia de descontrole às ações de governo e confundindo as pessoas. Por outro lado, revelou a contribuição das autoridades nesse processo, ao terem estendido a recomendação da vacinação para além de áreas de matas, abrangendo também áreas urbanas. Para nós, a mudança na instrução num momento particular de férias, entre o final de 2007 e início de 2008, pode ter sido decisivo para o dimensionamento exacerbado por parte da imprensa, que, em vez de esclarecer, confundiu ainda mais a cabeça das pessoas. Isso acabou dando a conotação de uma epidemia que não houve.

Para a saúde pública, que lida permanentemente com situações de risco, é preciso refletir sobre a melhor forma de divulgar os dados a fim de se evitar ou, pelo menos, minimizar os possíveis problemas que possam ocorrer. Em contextos de epidemia, a imprensa se converte numa instância importante na comunicação desse risco por disseminar as informações para um maior número de pessoas. Nesse sentido, as autoridades devem ter em mente que uma melhor cobertura depende de um maior comprometimento e abertura em relação aos veículos, buscando sensibilizá-los sobre a importância de se falar em saúde e estimulando, com isso, um conhecimento mais amplo dos jornalistas que cobrem a área.

\section{REFERÊNCIAS}

BARATA, Rita de Cássia Barradas. Meningite: uma doença sob censura? São Paulo: Cortez, 1988.

Saúde e direito à informação. Cadernos de Saúde Pública, Rio de Janeiro, v. 6, n. 4, p. 385-99, out.-dez. 1990. 
CHARAUDEAU, Patrick; MAINGUENEAU, Dominique. Dicionário de análise do discurso. 2 ed. São Paulo: Contexto, 2008.

DP - Diario de Pernambuco. Descartada epidemia de febre amarela. Recife, Diário de Pernambuco, Editoria Cidades, a. 183, n. 10, Editoria Brasil, 10 jan. 2008a. Disponível em: <http://www.pernambuco.com/diario/2008/01/10/brasil1_0.asp>. Acesso em: 30 set. 2011.

Crescem casos de efeitos colaterais. Diario de Pernambuco, Editoria Brasil, 29 jan. 2008b.

FERRAZ, Luiz Marcelo R. Epidemia e memória: narrativas jornalísticas na construção discursiva sobre a dengue. 2010.250 fl. Dissertação (Mestrado em Comunicação) - Universidade Federal de Pernambuco, Recife, 2010.

FOUCAULT, Michel. O nascimento da clínica. Trad. de Roberto Machado. 6 ed. Rio de Janeiro: Forense Universitária, 2006. A arqueologia do saber. 7. ed. Rio de Janeiro: Forense, 2007.

GOMES, Isaltina M. de Azevedo Mello; FERRAZ, Luiz Marcelo Robalinho. Ameaça e controle da gripe A (H1N1): uma análise discursiva de Veja, IstoÉ e Época. In: CONGRESO ALAIC, X, 2010, Bogotá. Anais... Bogotá: Alaic, 2010.

JC - Jornal do Commercio. Procura por vacina preocupa médicos. Recife, Jornal do Commercio, Editoria Cidades, a. 90, n. 12,12 jan. $2008 a$.

Um milhão se vacinaram se necessidade em GO. Recife, Jornal do Commercio, Editoria Brasil, a. 90, n. 23, 23 jan. 2008b.

FSP - Manual de redação. São Paulo: Publifolha, 1992.

MS - Ministério da Saúde. Situação da febre amarela silvestre no Brasil, 2007 e 2008. Brasília: Secretaria de Vigilância em Saúde, abr. 2008.

ORLANDI, Eni Puccinelli. As formas do silêncio: no movimento dos sentidos. 6. ed. Campinas: Editora da Unicamp, 2007.

ROUQUAYROL, Maria Zélia; ALMEIDA FILHO, Naomar de (Org.). Epidemiologia e saúde. 6. ed. Rio de Janeiro: Medsi, 2003.

SILVA, Luiz Jacintho da; ANGERAMI, Rodrigo Nogueira. Viroses emergentes no Brasil. Rio de Janeiro: Fiocruz, 2008.

SOTERO, Tatiana. Recife volta a oferecer vacina. Diario de Pernambuco, Recife: a. 183, n. 25, 25 jan. 2008. Disponível em: <http://www.pernambuco.com/diario/2008/01/25/brasil2_1.asp>. Acesso em: 30 set. 2011.

UVJARI, Stefan Cunha. A história e suas epidemias: a convivência do homem com os microorganismos. Rio de Janeiro / São Paulo: Senac, 2003. 
VEJA. A epidemia nacional do medo. São Paulo, n. 213, p. 24-29, 4 out. 1972.

VEYRET, Yvette; RICHEMOND, Nancy Meschinet. Definições e vulnerabilidades do risco. In: VEYRET, Yvette (Org.). Os riscos: o homem como agressor e vítima do meio ambiente. São Paulo: Contexto, 2007. p. 25-46.

Recebido em: 09.04.2012 / Aceito em: 04.06.2012 